\title{
Potential of diffusion-weighted imaging in magnetic resonance enterography to identify neoplasms in the ileocecal region: Use of ultra-high b-value diffusion-weighted imaging
}

\author{
HAO YU, CUI FENG, ZI WANG, JIANJUN LI, YANCHUN WANG, \\ XUEMEI HU, ZHEN LI, YAQI SHEN and DAOYU HU \\ Department of Radiology, Tongji Hospital, Tongji Medical College, Huazhong University of \\ Science and Technology, Wuhan, Hubei 430030, P.R. China
}

Received November 23, 2018; Accepted May 13, 2019

DOI: $10.3892 / 01.2019 .10441$

\begin{abstract}
Patients with chronic inflammatory bowel disease have an increased risk of colorectal cancer, and the differentiation between neoplastic and inflammatory lesions often poses a clinical dilemma. The aim of the present study was to investigate whether diffusion-weighted (DW) magnetic resonance (MR) enterography with ultra-high b-value facilitates the identification of neoplastic lesions in the ileocecal region. A total of 76 patients (22 patients with neoplasms, 26 inflammatory lesions and 28 normal subjects) from 292 cases of suspected bowel disorders were included in the present study. All patients were examined with conventional MR enterography and DW imaging (DWI) with seven different b-values $\left(400,600,800,1,000,1,200,1,500\right.$ and $\left.3,000 \mathrm{sec} / \mathrm{mm}^{2}\right)$ in a 3T MR scanner. DWI scans with different b-values were analyzed independently by two radiologists for the presence of ileocecal lesions. The signal intensity of the majority of inflammatory lesions and normal bowel segments gradually decreased to the background intensity with increasing b-values; however, neoplastic lesions demonstrated relative hyperintensity compared with the background. In addition, $\sim 76 \%$ of the positive findings from $b=3,000 \mathrm{sec} / \mathrm{mm}^{2}$ DWI were neoplasms. In conclusion, a lesion with consistently high signal intensity from DWI images with b-values increasing to $3,000 \mathrm{sec} / \mathrm{mm}^{2}$ indicated the presence of neoplasms. The results suggested that ultra-high $\mathrm{b}$-value $\left(3,000 \mathrm{sec} / \mathrm{mm}^{2}\right)$ imaging may aid the clinical differentiation of neoplasms from benign conditions.
\end{abstract}

Correspondence to: Dr Yaqi Shen, Department of Radiology, Tongji Hospital, Tongji Medical College, Huazhong University of Science and Technology, 1095 Jiefang Avenue, Wuhan, Hubei 430030, P.R. China

E-mail: yqshen@hust.edu.cn

Key words: magnetic resonance imaging, diffusion-weighted imaging, ileocecum, inflammation, neoplasm

\section{Introduction}

Chronic right lower quadrant pain is a clinical presentation for a spectrum of neoplastic and inflammatory diseases that may affect the ileocecal region $(1,2)$. A variety of structures may be pathologically involved, including the cecum, appendix, ileocecal valve and/or terminal ileum; thus, clinically differentiating the source of right lower quadrant pain is challenging (2-4).

At present, cross-sectional imaging, including computed tomography (CT) enterography and magnetic resonance enterography (MRE), serve important roles in the detection of bowel lesions (5-7). Recent guidelines regarding patient preparation and acquisition for cross-sectional small bowel and colonic imaging have been established (8). Differentiating between neoplastic and inflammatory diseases by their morphological appearance via imaging may be ambiguous due to the considerable overlap in conventional CT or MR features, including increased wall thickness, luminal narrowing and enlarged adjacent lymph nodes $(9,10)$. Inflammatory bowel disease increases the risk of small bowel and colonic adenocarcinoma, but may also mimic these malignancies upon imaging (11); thus, diagnosing certain cancer types in such patients is difficult $(9,12)$.

Diffusion weighted imaging (DWI) is a promising technique that measures the random motion of water molecules in biological tissues (5,13-15). DWI has been widely applied for the differentiation of neoplasms and the evaluation of therapeutic response in the solid abdominal viscera $(16,17)$. Additionally, DWI may be employed in clinical MRE examination, providing similar information to contrast-enhanced imaging in cases where the latter is contraindicated, including pregnancy, allergy to contrast agents and renal insufficiency $(13,18)$. The b-value of a DWI sequence indicates the strength of the diffusion-sensitizing gradient, which in part, determines image contrast (19-21). Previous studies have demonstrated the utility of higher b-values, $>1,000 \mathrm{sec} / \mathrm{mm}^{2}$, for the detection of breast (22) and pancreatic (20) cancer; however, the majority of MRE-based analyses have employed two or three b-values from $0-1,000 \mathrm{sec} / \mathrm{mm}^{2}$ for DWI $(18,23-25)$. At present, higher $\mathrm{b}$-values in DWI have not been investigated in this field. 
Therefore, the present study aimed to evaluate the potential of DWI with ultra-high b-values for the identification of neoplasms with endoscopic and surgical data as the reference standard.

\section{Patients and methods}

Patient enrolment. The institutional review board of Tongji Hospital (Wuhan, China) approved this retrospective study and the requirement for informed consent was waived. Analysis of the Tongji Hospital database identified the records from 292 MRE-based examinations of patients with suspected gastrointestinal diseases between September 2014 and December 2016. Among these patients, 86 MRE examinations met the following inclusion criteria: i) Ileocecal segments were completely assessed by endoscopy or surgery along with histopathology results; ii) multiple b-values of DWI $(400,600,800$, $1,000,1,200,1,500$ and $3,000 \mathrm{sec} / \mathrm{mm}^{2}$ ) were included in the MRE protocol; and iii) no bowel surgery was performed prior to MRE examination. Of the $86 \mathrm{MRE}$ examinations meeting these criteria, 6 duplicate MRE examinations for follow-up evaluation and 4 patients with inadequate DWI images due to extensive motion artifacts. The remaining 76 patients were included in the present study for analysis. A flow chart demonstrating the selection of patients is presented in Fig. 1.

MRE protocol. The MRE examination was performed using a 3.0-T GE MR scanner (Discovery MR750; GE Healthcare). All patients fasted for $\geq 6 \mathrm{~h}$ prior to the examination. To achieve adequate distension of the ileocecal segment, $\sim 1,500 \mathrm{ml}$ isosmotic mannitol solution was administered orally to each patient $\sim 45$ min prior to MR scanning. To reduce bowel peristalsis, $10 \mathrm{mg}$ anisodamine was administered intramuscularly $5 \mathrm{~min}$ prior to the examination in patients without contraindications, including glaucoma and/or prostatic hypertrophy. All patients were routinely scanned with a 32-channel phased-array body coil in the supine position. The MRE protocol is summarized in Table I. DW images were acquired in the transverse plane using the single shot echo planar imaging technique with parallel imaging and fat suppression (7). Diffusion-encoding gradients were applied at seven b-values from $400-3,000 \mathrm{sec} / \mathrm{mm}^{2}(400$, $600,800,1,000,1,200,1,500$ and $\left.3,000 \mathrm{sec} / \mathrm{mm}^{2}\right)$. The number of excitations was six for non-zero b-values. The total duration of acquisition in the entire examination for every patient was $\leq 30 \mathrm{~min}$, depending on the respiratory rate of the patients.

Image analysis. All images were transferred to a workstation (AW 4.5; GE Healthcare). Apparent diffusion coefficient (ADC) maps were generated by a mono-exponential fit using $b=0$ and one of the seven $b$-values. Two experienced gastrointestinal radiologists independently analyzed the image sets of DWI with the seven b-values and corresponding ADC maps. To reduce any bias, the radiologists were blinded to clinical details and the ileocolonoscopy and surgical results of the patients. The seven image sets were reviewed in a random order with a time interval of 4 weeks between readouts. Any discrepancies between the results were resolved by consulting with a third more experienced radiologist. The consensus of results was employed for further statistical analysis.

For the assessment of the image sets, the b-value of the images and the corresponding ADC maps of ileocecal segments were evaluated as previously described $(18,23)$ with respect to: i) Bowel wall thickening ( $>3 \mathrm{~mm}$ ); and ii) increased signal on DW images for the lesion. Ileocolonoscopy or operative results served as the reference standards.

Statistical analysis. Statistical analyses were performed using SPSS software (version 19; IBM Corp.). Sensitivities, specificities, positive predictive values (PPVs) and negative predictive values (NPVs) for the detection of lesions on DWI with different b-values were calculated by comparison with the reference standards. The Youden Index (YI) was obtained using the formula: YI=sensitivity + specificity-1. High YI values indicated superior performances. Diagnostic performances of DWI with different b-values were compared using a $\chi^{2}$ test. $\mathrm{P}<0.05$ was considered to indicate a statistically significant difference. Interobserver agreements between the two independent radiologists for the results of the DWI were evaluated by $\kappa$ statistical analysis $(\kappa=0.00-0.20$, slight agreement; $\kappa=0.21-0.40$, fair agreement; $\kappa=0.41-0.60$, moderate agreement; $\kappa=0.61-0.80$, good agreement and $\kappa=0.81-1.00$, almost perfect agreement) (26).

\section{Results}

Patient demographics. A total of 76 patients were included in the present study, including 41 males (mean age, 45 years; age range, 20-81 years) and 35 females (mean age, 57 years; age range, 20-80 years), with an overall mean age of 51 years (age range, 20-81 years). Among these 76 patients, 22 patients were diagnosed with neoplasms and 26 patients were diagnosed with areas of inflammation according to histopathological analysis of samples obtained following endoscopy or surgery. The ileocecal segments of the remaining 28 patients were normal. A summary of the diagnoses for the 76 patients is presented in Table II. Interobserver agreements from the results of the two radiologists were rated as good to perfect. The $\kappa$ values were $0.688-0.881$ for DWI with different $b$-values (Table III).

Performances of DWI with different $b$-values for the detection of lesions. The sensitivities, specificities, PPVs, NPVs and YI from DWI with different b-values $(400,600,800,1,000,1,200$, 1,500 and $3,000 \mathrm{sec} / \mathrm{mm}^{2}$ ) for detecting ileocecal lesions are presented in Table III. DWI with low b-values achieved higher sensitivity with a relatively lower specificity, while the specificity was increased in DWI with higher b-values. The YI reached the maximum (0.702) when the b-value of DWI was $800 \mathrm{sec} / \mathrm{mm}^{2}$, but then decreased as the b-value increased (Fig. 2). The diagnostic performances of the seven b-values for DWI were significantly different compared with each other, except for three groups [DWI with $b=600$ and $800 \mathrm{sec} / \mathrm{mm}^{2}$ $(\mathrm{P}=0.250)$; DWI with $\mathrm{b}=800$ and $1,000 \mathrm{sec} / \mathrm{mm}^{2}(\mathrm{P}=0.125)$; and DWI with $\mathrm{b}=1,000$ and $\left.1,200 \mathrm{sec} / \mathrm{mm}^{2}(\mathrm{P}=0.125)\right]$.

Effects of variable b-values on MRI-based diagnosis. The results of DWI using different b-values are presented in Table IV. The percentages of neoplastic lesions were determined via DWI with different b-values (Fig. 3). The signal intensities of inflammatory lesions and normal ileocecal segments decreased to background levels with increasing 
Table I. Magnetic resonance enterography parameter settings in a 3.0T MR scanner.

\begin{tabular}{|c|c|c|c|c|}
\hline Parameter & $\begin{array}{l}\text { Coronal/axial } \\
\text { SSFSE }\end{array}$ & $\begin{array}{l}\text { Coronal/axial } \\
\text { FIESTA }\end{array}$ & $\begin{array}{l}\text { Coronal/axial } \\
\text { LAVA }\end{array}$ & $\begin{array}{c}\text { Axial diffusion-weighted } \\
\text { imaging }\end{array}$ \\
\hline TR, msec & A respiratory cycle & 3.2 & 3.8 & A respiratory cycle \\
\hline TE, msec & 68 & 1.2 & 1.7 & 80 \\
\hline Flip Angel, ${ }^{\circ}$ & 90 & 45 & 15 & 90 \\
\hline Matrix, pixels & $288 \times 288$ & $288 \times 288$ & $260 \times 210$ & $160 \times 128$ \\
\hline Slice thickness, $\mathrm{mm}$ & $4 / 5$ & $4 / 5$ & $4.2 / 5.0$ & 6 \\
\hline Intersection gap, mm & $1 / 1$ & $1 / 1$ & $0 / 0$ & 1 \\
\hline Field of view, $\mathrm{cm}^{2}$ & Variable & Variable & Variable & $38 \times 30.4$ \\
\hline Number of excitations & 0.7 & 1 & 0.53 & 6 \\
\hline Fat saturation & Spectral & Spectral & N.A. & Fat \\
\hline
\end{tabular}

FIESTA, fast imaging employing steady-state acquisition; LAVA, liver acquisition with volume acceleration sequence; N.A., not applicable; SSFSE, single shot fast spin echo; TR, repetition time; TE, echo time.

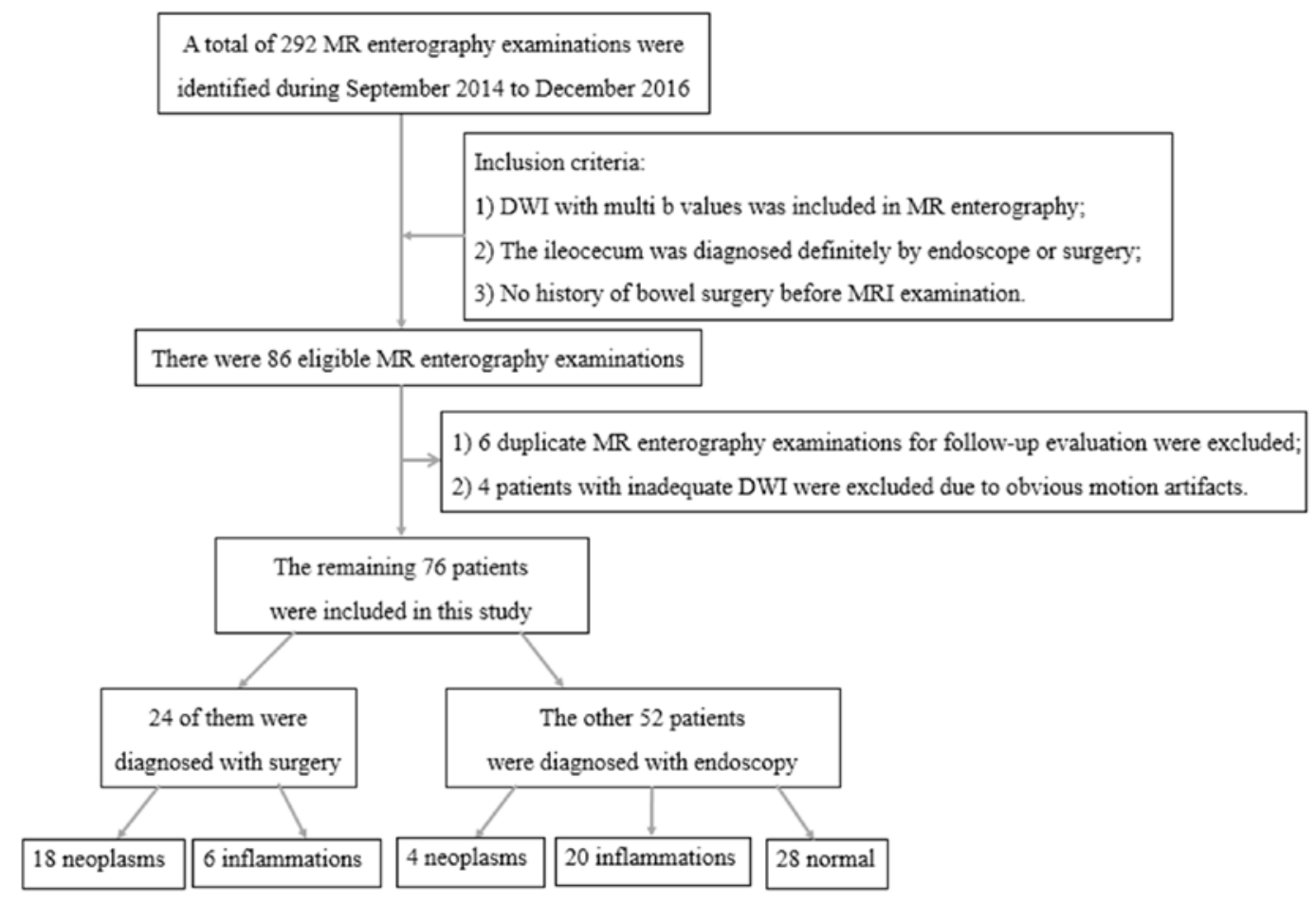

Figure 1. Flow chart of the enrolment process of patients in the present study. MR, magnetic resonance; MRI, magnetic resonance imaging; DWI, diffusion-weighted imaging.

b-values (Fig. 4); however, the neoplasms exhibited a high signal intensity relative to the background at high b-values (Fig. 5). As presented in Table IV and Fig. 3, the ratio of neoplasms to other lesions detected by DWI became greater with increasing b-values. Additionally, $76 \%$ of high signal intensity lesions on DWI with $b=3,000 \mathrm{sec} / \mathrm{mm}^{2}$ were neoplasms; 6 patients with inflammatory lesions (3 patients diagnosed with Crohn's disease, 2 with chronic mucosal inflammation with acute phase alterations, and 1 patient with appendicitis and a peri-appendiceal abscess) demonstrated a relatively high signal intensity on DWI with $b=3,000 \mathrm{sec} / \mathrm{mm}^{2}$. An appendiceal myxoma was deemed normal when b-values
$>1,200 \mathrm{sec} / \mathrm{mm}^{2}$ were applied and two adenocarcinomas were not visible with $b=3,000 \mathrm{sec} / \mathrm{mm}^{2}$ DWI.

\section{Discussion}

DWI is recommended for routine use by the European Society of Gastrointestinal and Abdominal Radiology (ESGAR) and the European Society of Pediatric Radiology (ESPR) in MRE-based assessments of inflammatory bowel disease with an upper range of $b$-values between $600-900 \mathrm{sec} / \mathrm{mm}^{2}$ (8). In the present study, DWI with $b=800 \mathrm{sec} / \mathrm{mm}^{2}$ achieved the highest YI value in the detection of neoplastic and inflammatory 
Table II. Diagnosis of patients included in the present study.

\begin{tabular}{lcc}
\hline Diagnosis & $\begin{array}{c}\text { Number } \\
\text { of patients }\end{array}$ & $\begin{array}{c}\text { Sex } \\
\text { (male:female), } \mathrm{n}\end{array}$ \\
\hline Neoplasms & 22 & $9: 13$ \\
Stromal tumor & 2 & $0: 2$ \\
Adenocarcinoma & 13 & $4: 9$ \\
Lymphoma & 5 & $3: 2$ \\
Sarcoma & 1 & $1: 0$ \\
Appendix myxoma & 1 & $1: 0$ \\
Inflammations & 26 & $19: 7$ \\
Crohn's disease & 11 & $9: 2$ \\
Intestinal tuberculosis & 4 & $2: 2$ \\
Ulcerative colitis & 1 & $0: 1$ \\
Mucosal chronic inflammation & 5 & $4: 1$ \\
Appendicitis & 5 & $4: 1$ \\
Normal ileocecal segments & 28 & $13: 15$ \\
Total & 76 & $41: 35$ \\
\hline
\end{tabular}

lesions among the seven assessed b-values. Overall, differences in lesion detection amongst b-values of $600-1,200 \mathrm{sec} / \mathrm{mm}^{2}$ were subtle, consistent with the ESGAR/ESPR recommendations (8). A higher b-value $\left(3,000 \mathrm{sec} / \mathrm{mm}^{2}\right)$ for DWI revealed the specificity for distinguishing neoplasms from bowel inflammation to be increased, with $76 \%$ of the positive findings representing neoplasms.

DWI has been widely used for the assessment of bowel diseases in recent years; however, the majority of studies have investigated the detection of neoplasms or inflamed bowel loops from normal loops using lower b-values (18,23,27-29). However, while the differentiation between bowel inflammation and neoplasms is clinically useful, it remains challenging when lower b values DWI are used, as neoplasms and inflammation are detected with high intensities at $b$-values between $400-1,200 \mathrm{sec} / \mathrm{mm}^{2}$. This is similar to the findings of a previous assessment of pancreatic adenocarcinoma on DWI with $\mathrm{b}=1,000 \mathrm{sec} / \mathrm{mm}^{2}$ (30). Due to the application of fast imaging acquisition techniques, gradient coils and improvements in MRI hardware, the use of higher b-value DWI has gained increasing attention in research and clinical practice $(22,31,32)$. Compared with standard b values $\left(\leq 1,000 \mathrm{sec} / \mathrm{mm}^{2}\right)$, higher $b$-values $\left(\geq 1,500 \mathrm{sec} / \mathrm{mm}^{2}\right)$ may enhance the image contrast between unaffected bowel and neoplasms, as the greater cellularity in the latter restricts free diffusion of water in the tumor tissues $(19,20)$.

The results of the present study demonstrated that the signal intensity of normal and inflamed bowel decreased to background level at b-values $>1,200 \mathrm{sec} / \mathrm{mm}^{2}$ (Fig. 4). At such b-values, neoplastic lesions exhibited relatively high intensity (Fig. 5) and the ratio of neoplasms in the positive DWI findings with higher b-values increased. These findings were consistent with previous studies $(19,20,32-34)$, which proposed that DWI analysis with higher b-values may provide sufficient background suppression to reduce the false-positive diagnoses of neoplasms. Similar findings have been reported in the pancreas; Fukukura et al (20) revealed that $b=1,500 \mathrm{sec} / \mathrm{mm}^{2}$ DWI improved the delineation

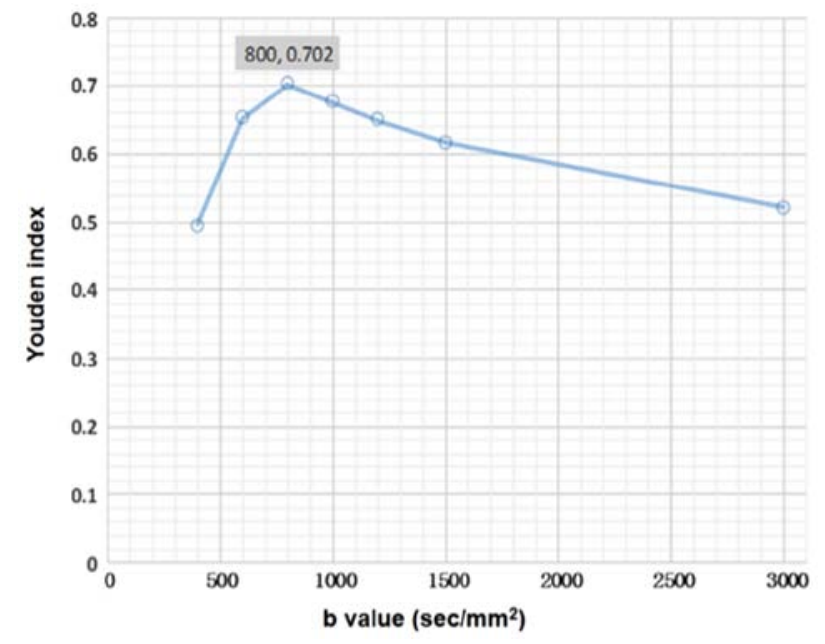

Figure 2. Tendency curve of the Youden Index from diffusion weighted imaging with different $b$-values for the detection of ileocecal lesions.

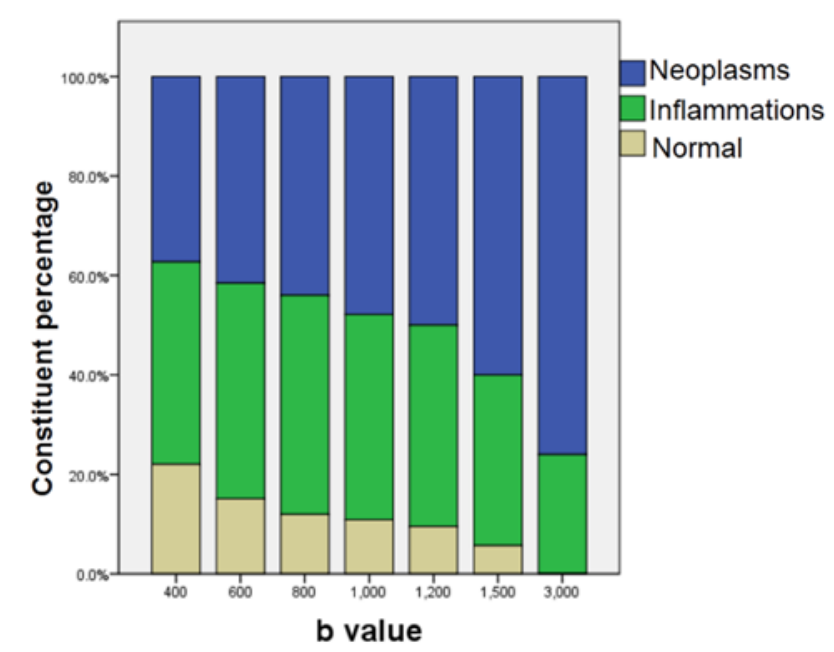

Figure 3. Percentages of neoplasms and inflammations in ileocecal segments from diffusion weighted imaging with different b-values $\left(\mathrm{sec} / \mathrm{mm}^{2}\right)$.

of pancreatic adenocarcinomas from pancreatitis. In the prostate, lesions with increased signal intensity from higher b-value images were predominantly tumors (82\%) (34).

In the present study, there were 6 cases of bowel inflammation demonstrating slight hyperintensity on DWI with $\mathrm{b}=3,000 \mathrm{sec} / \mathrm{mm}^{2}$. The basis of restricted diffusion in DWI is associated with the cellularity of tissues $(31,35)$; abscesses exhibit hyperintensity on high b-value $\left(3,000 \mathrm{sec} / \mathrm{mm}^{2}\right)$ DWI due to the abundance of inflammatory cells with restricted motion inside the abscess cavity (36). Thus, the high signal intensity of inflammatory lesions on high b-value DWI could be due to the accumulation of inflammatory cells or the formation of acute micro abscesses; however, further investigation is required. In addition, an appendiceal myxoma and two adenocarcinomas were not visible on the higher b-value DWI $\left(b=3,000 \mathrm{sec} / \mathrm{mm}^{2}\right)$ in the present study. This could be associated with the abundance of mucins (37), which was identified in these cases via histopathological analysis. Some of these shortcomings may be addressed by using a combination of conventional MRE sequences alongside high b-value DWI. 
Table III. Sensitivity, specificity, PPV, NPV and YI of diffusion-weighted imaging with different b-values for the detection of ileocecal lesions, and interobserver agreement between independent assessments by two radiologists.

\begin{tabular}{lcccccc}
\hline $\begin{array}{l}\text { b-value, } \\
\text { sec/mm }\end{array}$ & $\begin{array}{c}\text { Sensitivity } \\
(95 \% \mathrm{CI})\end{array}$ & $\begin{array}{c}\text { Specificity } \\
(95 \% \mathrm{CI})\end{array}$ & $\begin{array}{c}\text { PPVs } \\
(95 \% \mathrm{CI})\end{array}$ & $\begin{array}{c}\text { NPVs } \\
(95 \% \mathrm{CI})\end{array}$ & YI & $\kappa(95 \% \mathrm{CI})$ \\
\hline 400 & $0.958(0.846-0.993)$ & $0.536(0.342-0.720)$ & $0.780(0.649-0.873)$ & $0.882(0.623-0.979)$ & 0.494 & $0.789(0.629-0.950)$ \\
600 & $0.938(0.818-0.984)$ & $0.714(0.511-0.860)$ & $0.849(0.719-0.928)$ & $0.870(0.653-0.966)$ & 0.652 & $0.688(0.510-0.867)$ \\
800 & $0.917(0.791-0.973)$ & $0.786(0.5854-0.910)$ & $0.880(0.750-0.950)$ & $0.846(0.643-0.950)$ & 0.702 & $0.858(0.738-0.978)$ \\
1,000 & $0.854(0.766-0.961)$ & $0.821(0.624-0.932)$ & $0.891(0.766-0.961)$ & $0.767(0.624-0.932)$ & 0.676 & $0.754(0.603-0.904)$ \\
1,200 & $0.792(0.623-0.875)$ & $0.857(0.706-0.972)$ & $0.905(0.785-0.980)$ & $0.706(0.517-0.831)$ & 0.649 & $0.841(0.719-0.963)$ \\
1,500 & $0.688(0.579-0.843)$ & $0.929(0.750-0.988)$ & $0.943(0.805-0.991)$ & $0.634(0.500-0.804)$ & 0.616 & $0.842(0.720-0.963)$ \\
3,000 & $0.521(0.374-0.665)$ & $1(0.850-1.000)$ & $1.000(0.834-1.000)$ & $0.549(0.405-0.686)$ & 0.521 & $0.881(0.767-0.994)$ \\
\hline
\end{tabular}

CI, confidence interval; NPVs, negative predictive values; PPVs, positive predictive values; YI, Youden index.

Table IV. Number of positive results on DWI with different b-values.

\begin{tabular}{|c|c|c|c|c|c|}
\hline $\begin{array}{l}\text { b-value, } \\
\mathrm{sec} / \mathrm{mm}^{2}\end{array}$ & $\begin{array}{l}\text { Positive } \\
\text { DWI findings }\end{array}$ & Neoplasms, $\mathrm{n}^{\mathrm{a}}$ & $\begin{array}{l}\text { Inflammatory } \\
\text { lesions, } \mathrm{n}^{\mathrm{a}}\end{array}$ & Normal, $\mathrm{n}^{\mathrm{a}}$ & $\begin{array}{l}\% \text { of positive findings } \\
\text { representing neoplasms }\end{array}$ \\
\hline 400 & 59 & 22 & 24 & 13 & 37.3 \\
\hline 600 & 53 & 22 & 23 & 8 & 41.5 \\
\hline 800 & 50 & 22 & 22 & 6 & 44.0 \\
\hline 1,000 & 46 & 22 & 19 & 5 & 47.8 \\
\hline 1,200 & 42 & 21 & 17 & 4 & 50.0 \\
\hline 1,500 & 35 & 21 & 12 & 2 & 60.0 \\
\hline 3,000 & 25 & 19 & 6 & 0 & 76.0 \\
\hline
\end{tabular}

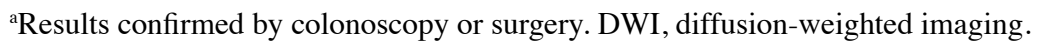
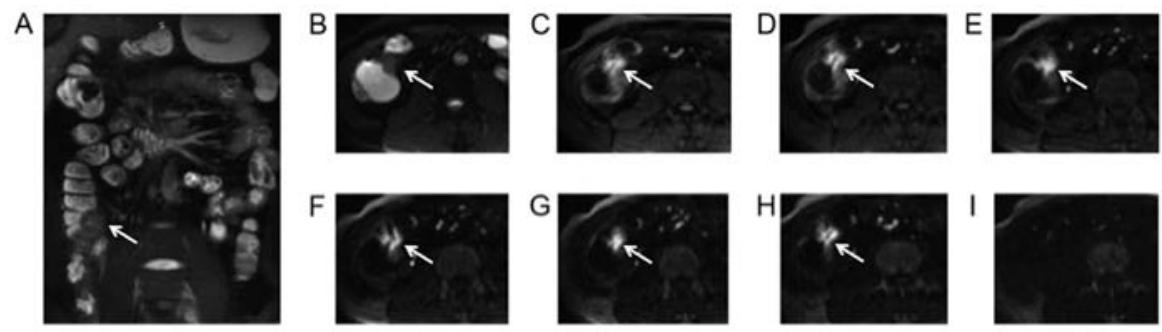

Figure 4. Ileocecal valve of a 20-year-old male clinically diagnosed with Crohn's disease. The ileocecal valve (arrow) was thickened as determined by (A) coronal single shot fast spin echo T2 weighted image magnetic resonance enterography and (B) DWI with $b=0$ sec/mm². Analysis demonstrated high intensity on DWI with (C) $b=400 \mathrm{sec} / \mathrm{mm}^{2}$, (D) $b=600 \mathrm{sec} / \mathrm{mm}^{2}$, (E) $b=800 \mathrm{sec} / \mathrm{mm}^{2}$, (F) b=1,000 sec/mm ${ }^{2}$, (G) b=1,200 sec/mm $\mathrm{mm}^{2}$ and $\mathrm{b}=1,500 \mathrm{sec} / \mathrm{mm}^{2}$. (I) The lesion was indistinguishable from the background on DWI with $\mathrm{b}=3,000 \mathrm{sec} / \mathrm{mm}^{2}$. DWI, diffusion-weighted imaging.
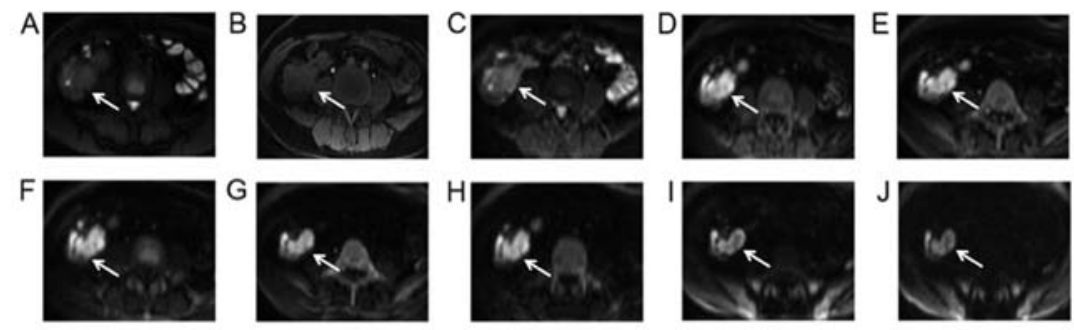

Figure 5. A 37-year-old female with ileocecal adenocarcinoma cancer diagnosed by pathological analysis following surgery. The lesion (arrow) was irregular and extended to the enteric cavity as determined via (A) conventional axial T2 weighted image, (B) $\mathrm{T} 1 \mathrm{weighted}$ image and $(\mathrm{C}) \mathrm{DWI}$ with $\mathrm{b}=0 \mathrm{sec} / \mathrm{mm}^{2}$. The lesion demonstrated a sustained high signal intensity on DWI with increasing b-values of (D) b=400 sec/mm ${ }^{2},(E) b=600 \mathrm{sec} / \mathrm{mm}^{2},(\mathrm{~F}) \mathrm{b}=800 \mathrm{sec} / \mathrm{mm}^{2}$, (G) $b=1,000 \mathrm{sec} / \mathrm{mm}^{2}$, (H) $b=1,200 \mathrm{sec} / \mathrm{mm}^{2}$, (I) $b=1,500 \mathrm{sec} / \mathrm{mm}^{2}$ and $(\mathrm{J}) \mathrm{b}=3,000 \mathrm{sec} / \mathrm{mm}^{2}$. DWI, diffusion-weighted imaging. 
In conclusion, persistent hyperintensity of ileocecal lesions on DWI with higher b-values suggests the presence of neoplasms rather than inflammatory bowel conditions. Thus, the use of higher b-values for DWI in MRE may aid in the distinction of neoplasms from other bowel-associated pathologies. Due to the limitations in sensitivity and decreased signal to noise ratios, high b-value DWI may be most valuable as an adjunct sequence to DWI performed with conventional b-values $\left(\sim 800 \mathrm{sec} / \mathrm{mm}^{2}\right)$.

\section{Acknowledgements}

The authors would like to thank Professor John Morelli, a radiologist from St. John's Medical Center, for reading and commenting on this manuscript.

\section{Funding}

The present study was supported by the National Natural Science Foundation of China (grants nos. 81701657, 81771801 and 81571642) and the Fundamental Research Funds for the Central Universities (grant no. NO.2017KFYXJJ126).

\section{Availability of data and materials}

The datasets used and/or analyzed during the current study are available from the corresponding author on reasonable request.

\section{Authors' contributions}

HY wrote the main manuscript. HY, CF, ZW and JJL searched the database and acquired patients. HY, CF, XMH, ZL, YQS and DYH designed the study. HY, CF, ZW, JJL and YCW performed data analysis. JJL and YCW interpreted and checked data. $\mathrm{CF}, \mathrm{XMH}, \mathrm{ZL}, \mathrm{YQS}$ and DYH contributed to the manuscript revisions. All authors read and approved the final manuscript.

\section{Ethics approval and consent to participate}

The present study was approved by the institutional review board of Tongji Hospital and informed consent was waived.

\section{Patient consent for publication}

Not applicable.

\section{Competing interests}

The authors declare that they have no competing interests.

\section{References}

1. Purysko AS, Remer EM, Filho HML, Bittencourt LK, Lima RV and Racy DJ: Beyond appendicitis: Common and uncommon gastrointestinal causes of right lower quadrant abdominal pain at multidetector CT. Radiographics 31: 927-947, 2011.

2. Patel NB and Wenzke DR: Evaluating the patient with right lower quadrant pain. Radiol Clin North Am 53: 1159-1170, 2015

3. Xie X, Zhou Z, Song Y, Wang W, Dang C and Zhang H: Differences between carcinoma of the cecum and ascending colon: Evidence based on clinical and embryological data. Int J Oncol 53: 87-98, 2018.
4. Hoeffel C, Crema MD, Belkacem A, Azizi L, Lewin M, Arrivé L and Tubiana JM: Multi-detector row CT: Spectrum of diseases involving the ileocecal area. Radiographics 26: 1373-1390, 2006.

5. Rimola J, Rodriguez S, Garcia-Bosch O, Ordás I, Ayala E, Aceituno M, Pellisé M, Ayuso C, Ricart E, Donoso L and Panés J: Magnetic resonance for assessment of disease activity and severity in ileocolonic Crohn's disease. Gut 58: 1113-1120, 2009.

6. Amzallag-Bellenger E, Soyer P, Barbe C, Diebold MD, Cadiot G and Hoeffel C: Prospective evaluation of magnetic resonance enterography for the detection of mesenteric small bowel tumours. Eur Radiol 23: 1901-1910, 2013.

7. Dohan A, Taylor S, Hoeffel C, Barret M, Allez M, Dautry R, Zappa M, Savoye-Collet C, Dray X, Boudiaf M, et al: Diffusion-weighted MRI in Crohn's disease: Current status and recommendations. J Magn Reson Imaging 44: 1381-1396, 2016.

8. Taylor SA, Avni F, Cronin CG, Hoeffel C, Kim SH, Laghi A, Napolitano M, Petit P, Rimola J, Tolan DJ, et al: The first joint ESGAR/ESPR consensus statement on the technical performance of cross-sectional small bowel and colonic imaging. Eur Radiol 27: 2570-2582, 2017.

9. Barral M, Dohan A, Allez M, Boudiaf M, Camus M, Laurent V, Hoeffel C and Soyer P: Gastrointestinal cancers in inflammatory bowel disease: An update with emphasis on imaging findings. Crit Rev Oncol Hematol 97: 30-46, 2016.

10. Hristova L, Soyer P, Hoeffel C, Marteau P, Oussalah A, Lavergne-Slove A, Boudiaf M, Dohan A and Laurent V: Colorectal cancer in inflammatory bowel diseases: CT features with pathological correlation. Abdom Imaging 38: 421-435, 2013.

11. De Lerma BA, Perletti G, Bonapace IM and Monti E: Inflammatory cues acting on the adult intestinal stem cells and the early onset of cancer (review). Int J Oncol 45: 959-968, 2014.

12. Biancone L, Armuzzi A, Scribano ML, D'Inca R, Castiglione F, Papi C, Angelucci E, Daperno M, Mocciaro F, Riegler G, et al: Inflammatory bowel disease phenotype as risk factor for cancer in a prospective multicentre nested case-control IG-IBD study. J Crohns Colitis 10: 913-924, 2016.

13. Park SH: DWI at MR enterography for evaluating bowel inflammation in Crohn disease. AJR Am J Roentgenol 207: 40-48, 2016.

14. Li H, Liang L, Li A, Hu Y, Hu D, Li Z and Kamel IR: Monoexponential, biexponential, and stretched exponential diffusion-weighted imaging models: Quantitative biomarkers for differentiating renal clear cell carcinoma and minimal fat angiomyolipoma. J Magn Reson Imaging 46: 240-247, 2017.

15. Bittencourt LK, Matos C and Coutinho AC Jr: Diffusion-weighted magnetic resonance imaging in the upper abdomen: Technical issues and clinical applications. Magn Reson Imaging Clin N Am 19: 111-131, 2011.

16. Huh J, Kim KJ, Park SH, Park SH, Yang SK, Ye BD, Park SH, Han K and Kim AY: Diffusion-weighted MR enterography to monitor bowel inflammation after medical therapy in Crohn's disease: A prospective longitudinal study. Korean J Radiol 18: 162-172, 2017.

17. Wang YC, Hu DY, Hu XM, Shen YQ, Meng XY, Tang H and $\mathrm{Li} \mathrm{Z}$ : Assessing the early response of advanced cervical cancer to neoadjuvant chemotherapy using intravoxel incoherent motion diffusion-weighted magnetic resonance imaging: A pilot study. Chin Med J (Engl) 129: 665-671, 2016.

18. Seo N, Park SH, Kim KJ, Kang BK, Lee Y, Yang SK, Ye BD, Park SH, Kim SY, Baek S, et al: MR Enterography for the evaluation of small-bowel inflammation in crohn disease by using diffusion-weighted imaging without intravenous contrast material: A prospective noninferiority study. Radiology 278: 762-772, 2016.

19. Metens T, Miranda D, Absil J and Matos C: What is the optimal $\mathrm{b}$ value in diffusion-weighted MR imaging to depict prostate cancer at 3T? Eur Radiol 22: 703-709, 2012.

20. Fukukura Y, Shindo T, Hakamada H, Takumi K, Umanodan T, Nakajo M, Kamimura K, Umanodan A, Ideue J and Yoshiura T: Diffusion-weighted MR imaging of the pancreas: Optimizing b-value for visualization of pancreatic adenocarcinoma. Eur Radiol 26: 3419-3427, 2016.

21. Goshima S, Kanematsu M, Kondo H, Yokoyama R, Kajita K, Tsuge Y, Watanabe H, Shiratori Y, Onozuka M and Moriyama N: Diffusion-weighted imaging of the liver: Optimizing $b$ value for the detection and characterization of benign and malignant hepatic lesions. J Magn Reson Imaging 28: 691-697, 2008. 
22. Woodhams R, Inoue $\mathrm{Y}$, Ramadan S, Hata $\mathrm{H}$ and Ozaki $\mathrm{M}$ : Diffusion-weighted imaging of the breast: Comparison of b-values 1,000 s/mm² and 1,500 s/mm². Magn Reson Med Sci 12: 229-234, 2013.

23. Sirin S, Kathemann S, Schweiger B, Hahnemann ML, Forsting M, Lauenstein TC and Kinner S: Magnetic resonance colonography including diffusion-weighted imaging in children and adolescents with inflammatory bowel disease: Do we really need intravenous contrast? Invest Radiol 50: 32-39, 2015

24. Kim KJ, Lee Y, Park SH, Kang BK, Seo N, Yang SK, Ye BD Park SH, Kim SY, Baek S and Ha HK: Diffusion-weighted MR enterography for evaluating Crohn's disease: How does it add diagnostically to conventional MR enterography? Inflamm Bowel Dis 21: 101-109, 2015.

25. Li XH, Sun CH, Mao R, Huang SY, Zhang ZW, Yang XF Huang L, Lin JJ, Zhang J, Ben-Horin S, et al: Diffusion-weighted MRI enables to accurately grade inflammatory activity in patients of ileocolonic Crohn's disease: Results from an observational study. Inflamm Bowel Dis 23: 244-253, 2017.

26. Bouwense SA, van Brunschot $S$, van Santvoort HC, Besselink MG Bollen TL,Bakker OJ,Banks PA, Boermeester MA,Cappendijk VC, Carter R, et al: Describing peripancreatic collections according to the revised atlanta classification of acute pancreatitis: An international interobserver agreement study. Pancreas 46: 850-857, 2017.

27. Buisson A, Hordonneau C, Goutte M, Boyer L, Pereira B and Bommelaer G: Diffusion-weighted magnetic resonance imaging is effective to detect ileocolonic ulcerations in Crohn's disease. Aliment Pharmacol Ther 42: 452-460, 2015.

28. Liu W, Liu J, Xiao W and Luo G: A Diagnostic accuracy meta-analysis of CT and MRI for the evaluation of small bowel Crohn disease. Acad Radiol 24: 1216-1225, 2017.

29. Amzallag-Bellenger E, Soyer P, Barbe C, Nguyen TL, Amara $\mathrm{N}$ and Hoeffel C: Diffusion-weighted imaging for the detection of mesenteric small bowel tumours with magnetic resonance-enterography. Eur Radiol 24: 2916-2926, 2014.

30. Fukukura Y, Takumi K, Kamimura K, Shindo T, Kumagae Y, Tateyama A and Nakajo M: Pancreatic adenocarcinoma: Variability of diffusion-weighted MR imaging findings. Radiology 263: 732-740, 2012.
31. Pramanik PP, Parmar HA, Mammoser AG, Junck LR, Kim MM, Tsien CI, Lawrence TS and Cao Y: Hypercellularity components of glioblastoma identified by high b-value diffusion-weighted imaging. Int J Radiat Oncol Biol Phys 92: 811-819, 2015.

32. Agarwal HK, Mertan FV, Sankineni S, Bernardo M, Senegas J, Keupp J, Daar D, Merino M, Wood BJ, Pinto PA, et al: Optimal high $b$-value for diffusion weighted MRI in diagnosing high risk prostate cancers in the peripheral zone. J Magn Reson Imaging 45: 125-131, 2017.

33. Coolen J, De Keyzer F, Nafteux P, De Wever W, Dooms C, Vansteenkiste J, Derweduwen A, Roebben I, Verbeken E, De Leyn P, et al: Malignant pleural mesothelioma: Visual assessment by using pleural pointillism at diffusion-weighted MR imaging. Radiology 274: 576-584, 2015.

34. Quentin M, Schimmöller L, Arsov C, Rabenalt R, Antoch G, Albers $\mathrm{P}$ and Blondin D: Increased signal intensity of prostate lesions on high b-value diffusion-weighted images as a predictive sign of malignancy. Eur Radiol 24: 209-213, 2014.

35. Tasaki A, Asatani MO, Umezu H, Kashima K, Enomoto T, Yoshimura $\mathrm{N}$ and Aoyama H: Differential diagnosis of uterine smooth muscle tumors using diffusion-weighted imaging: Correlations with the apparent diffusion coefficient and cell density. Abdom Imaging 40: 1742-1752, 2015.

36. Tomar V, Yadav A, Rathore RK, Verma S, Awasthi R, Bharadwaj V, Ojha BK, Prasad KN and Gupta RK: Apparent diffusion coefficient with higher b-value correlates better with viable cell count quantified from the cavity of brain abscess. AJNR Am J Neuroradiol 32: 2120-2125, 2011.

37. Woodhams R, Kakita S, Hata H, Iwabuchi K, Umeoka S, Mountford CE and Hatabu H: Diffusion-weighted imaging of mucinous carcinoma of the breast: Evaluation of apparent diffusion coefficient and signal intensity in correlation with histologic findings. AJR Am J Roentgenol 193: 260-266, 2009. 